\title{
Sex-Related Differences in Locomotion and Climbing of C57BI/6NTac Mice in a Novel Environment
}

\author{
V. BORBÉLYOVÁ ${ }^{1}$, K. JANIŠOVÁ ${ }^{2}$, J. MYSLIVEČEK ${ }^{2}$, V. RILJAK ${ }^{2}$ \\ ${ }^{1}$ Institute of Molecular Biomedicine, Faculty of Medicine, Comenius University, Bratislava, Slovak \\ Republic, ${ }^{2}$ Department of Physiology, First Faculty of Medicine, Charles University, Prague, Czech \\ Republic
}

Received March 21, 2019

Accepted September 26, 2019

\section{Summary}

Laboratory mice in standard laboratory cages, besides horizontal and vertical locomotor activity, spontaneously display cage-bar related activities such as cage-grid climbing. Although, gridclimbing activity is one of the major components of spontaneous home-cage behavior of mice, its exact role is not fully understood. This study aimed to describe the sex-differences in coping with novelty and in spontaneous behavior of laboratory mice concerning the cage-climbing activity in an observerindependent open field test. Adult mice of both sexes (C57Bl/6NTac) underwent behavioral testing in LABORAS system. Female mice travelled significantly longer distance (by $30 \%$, $\mathrm{p}<0.05$ ) and showed higher grid-climbing activity (by $50 \%$, $\mathrm{p}<0.05)$ than males. Based on our results, the grid-climbing is a sex-dependent activity of mice, however, its exact role remains to be elucidated.
\end{abstract}

\section{Key words}

Automatic behavior registration • Gender differences • Gridclimbing activity • Mouse

\section{Corresponding author}

V. Riljak, Department of Physiology, First Faculty of Medicine, Charles University, Prague, Czech Republic. E-mail: vladimir.riljak@lf1.cuni.cz

\section{Introduction}

The open field test (OF) is used to assess the spontaneous locomotor activity of the rodents (Perals et al. 2017) and its significance in neuroscience was reviewed many times in the past (Walsh et al. 1976, Sturman et al. 2018). The movement of the animal across the arena is driven by two opposing vectors: the willingness to explore and the fear of the unknown environment (Sturman et al. 2018). When the animal is left for adaptation in the arena before the recording of its activity starts, the results bringing the insight into its spontaneous home-cage behavior. If the movement and exploratory activity of the animal throughout the arena are evaluated immediately after placing the animal to the arena, it serves as a paradigm of how the animal is coping with a novel environment (Kulesskaya et al. 2014). OF serves also as an unconditioned test for measuring anxiety and emotionality of rodents (Walsh et al. 1976, Kulesskaya et al. 2014). Thus, if interpreted correctly, it might describe the "personality" of the animal and its dynamics throughout the ontogeny (Perals et al. 2017). Since its initial use in 1930s, the OF has been developed from a simple and usually manual measurement of the locomotor activity of the rodents to a fully automated systems (such as Laboratory Animal Behaviour Observation, Registration, and Analysis System LABORAS) analyzing many different behavioral domains for short- or long-term observation period (Quinn et al. 2006). In the OF, two major types of behavioral categories, the horizontal (distance travelled, velocity of the movement) and the vertical (rearing and exploratory behavior) locomotor activity are usually analyzed (Quinn et al. 2006, Jandova et al. 2014, Schwarz et al. 2014). In standard laboratory cages, besides horizontal and vertical locomotor activity, laboratory mice spontaneously exhibit cage-bar related activities, such as bar gnawing, bar jumping and climbing on the cage lid (Nevison et al. 1999). It has previously been reported, that bar-related activities of mice might be 
either a form of motor routine (Buttner 1991) or attempting to leave the home-cage environment (Nevison et al. 1999). Bar-related activities of mice were also considered as repetitive stereotypic-like behavior since mice display this type of behavior several times and also in the same manner during the daytime (Nevison et al. 1999). It has been also indicated that cage-lid-related activity is associated with a coping response of mice reducing the captivity-induced stress (Mason 1991). On the other hand, the prevention of cage-climbing activity is associated with higher anxiety-like behavior of mice (Pietropaolo et al. 2007). Thus, it emphasizes the importance of cage-climbing activity during the mouse development, however, the exact meaning of either cageclimbing activity or other cage-bar-related interactions is not fully understood.

Therefore, the aim of the present study was to describe the sex-differences in coping with a novelty and in the spontaneous behavior concerning the cageclimbing activity of $\mathrm{C} 57 \mathrm{Bl} / 6 \mathrm{NTac}$ mice in the LABORAS system (LABORAS ${ }^{\mathrm{TM}}$, Metris, Hoofddorp, The Netherlands).

\section{Methods}

\section{Ethics statement}

All procedures have been conducted in accordance with the legislature of the Czech Republic and the EU legislature (European Convention for the Protection of Vertebrate Animals used for Experimental and other Scientific Purposes - Council of Europe No. 123, Strasbourg 1985), and the experimental protocol was approved by the Committee for the Protection of Experimental Animals of the $1^{\text {st }}$ Medical Faculty, Charles University, Prague and by the Ministry of Education of the Czech Republic under No MSMT-7063/2017-3.

\section{Animals and housing conditions}

In this study, C57B1/6NTac mice (females: $n=6$, males: $n=6$ ) were used. Adult animals ( 8 -week old) were purchased from the breeding colony Taconic (Taconic Biosciences, Rensselaer, NY, USA). The animals were maintained under controlled environmental conditions (12 h:12 h light: dark regime with lights on at 06:00 a.m. and lights off at 6:00 p.m.; temperature $22 \pm 2{ }^{\circ} \mathrm{C}$ and relative humidity $55 \pm 10 \%$ ). Mice had ad libitum access to standard food and water. During the experiment, the mice were group-housed ( 3 per cage) in polycarbonate cages $(26 \times 20 \times 14 \mathrm{~cm})$.

\section{Behavioral testing}

To examine spontaneous locomotor activity, exploratory behavior and cage-lid climbing activity of adult mice (10-week-old) in an unknown environment, the Laboratory Animal Behaviour Observation, Registration, and Analysis System (LABORAS ${ }^{\mathrm{TM}}$, Metris, Hoofddorp, The Netherlands) was used. The LABORAS system (Fig. 1) is equipped with a so-called sensor platform that electronically measures the mechanical vibrations caused by the movement of the animal. These vibration signals are transformed by the LABORAS software into the particular behavioral category (Van de Weerd et al. 2001). The LABORAS software reliably recognizes several behaviors of laboratory rodents using the latest pattern recognition and signal analysis. Each type of behavior has its own unique signal characteristics which can be detected by the LABORAS software to identify the corresponding behavior. Each movement of the animal has its own unique frequency and amplitude pattern allowing the separation of behavioral categories, which further can be distinguished by the computer (LABORAS ${ }^{\mathrm{TM}}$, Metris, Hoofddorp, The Netherlands) (Van de Weerd et al. 2001).

Following a 30-min habituation period for the testing room, the animals were individually placed to the LABORAS cage with the bedding used in the home cage of animals. Only one platform of the LABORAS system was used. During the recording, the experimenters were in an adjacent room. The spontaneous behavior of mouse was recorded for $10 \mathrm{~min}$ and then it was returned to its home cage. Behavioral phenotyping was conducted in the light phase of the light/dark cycle (between 9:00-11:00). Different sets of LABORAS cages were used for males and females. The light intensity in cages of males and females was 100-120 lx. The LABORAS apparatus with cages were maintained in the same positions in the room. Both LABORAS cages were placed in comparable positions on a desk in proximity to walls, a door and light sources (Fig. 1). To remove any residual smell of the previously tested animal, the cage was cleaned with a damp cloth containing $70 \%$ ethanol between sessions.

The analyzed behavioral parameters were as follows: horizontal locomotor activity (total distance moved $[\mathrm{m}]$, average velocity of the movement $[\mathrm{cm} / \mathrm{s}])$, vertical locomotor activity (rearing frequency [n] and rearing duration $[\mathrm{s}]$ ) and grid-climbing activity (climbing frequency $[\mathrm{n}]$ and climbing duration $[\mathrm{s}]$ ). 


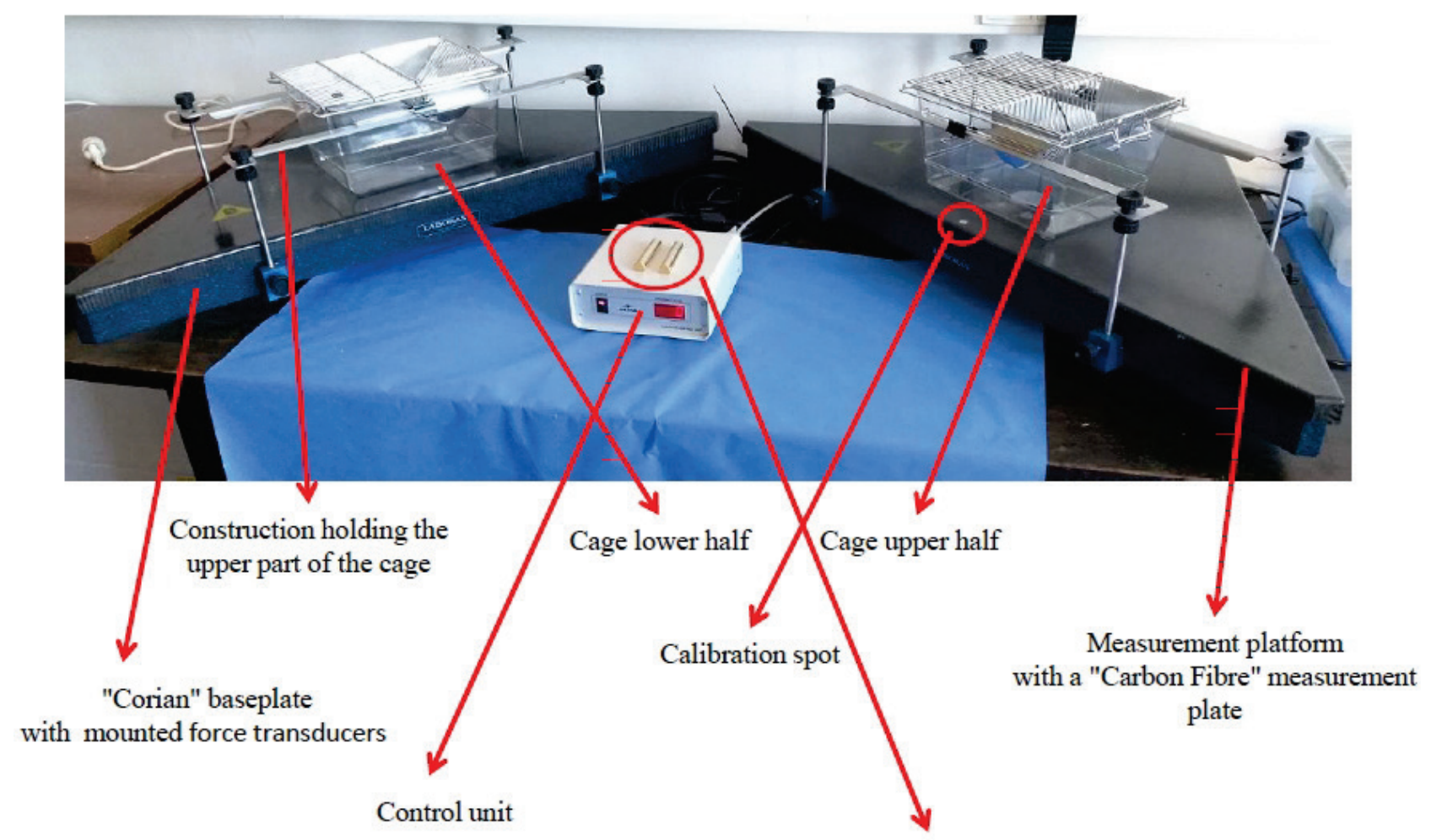

Calibration bars

Fig. 1. The LABORAS system.

\section{Statistical analysis}

Statistical analysis was performed using GraphPad Prism version 8.0.2 (GraphPad Software, Inc., CA, USA). To analyze sex differences in the behavior of mice, unpaired Students' two-tailed $t$-test was used. To assess sex differences in the process of habituation for the novel environment, two-way repeated measures of ANOVA followed by Bonferroni's multiple comparison post-hoc test was used. $\mathrm{p}<0.05$ were considered statistically significant. Data are presented as mean plus standard error of the mean (SEM).

\section{Results}

Significant sex differences were found in horizontal locomotor activity, with adult male mice travelling significantly shorter distance (by $30 \%, \mathrm{t}_{9}=2.50$, $\mathrm{p}<0.05$, Fig. 2A) and moving slower (by $30 \%, \mathrm{t}_{9}=2.50$, $\mathrm{p}<0.05$, Fig. 2B) than females. In terms of distance moved, the process of habituation for the novel environment (Fig. 2C) was assessed in minute-by-minute time bins in both females and males. Two-way repeated measures of ANOVA showed a significant effect of time $\left(\mathrm{F}_{2,72}=6.51, \mathrm{p}<0.01\right)$, but not $\operatorname{sex}\left(\mathrm{F}_{1,10}=1.83, \mathrm{p}=0.21\right)$ on the process of habituation. The interaction between these two factors was not statistically significant $\left(\mathrm{F}_{9,90}=0.22\right.$, $\mathrm{p}=0.99$ ).

Although, females displayed higher rearing activity (by $40 \%$ ) than males, this difference was statistically not significant (rearing frequency: $\mathrm{t}_{10}=1.36$, $\mathrm{p}=0.20$, Fig. $3 \mathrm{~A}$; rearing duration: $\mathrm{t}_{10}=1.22, \mathrm{p}=0.25$, Fig. 3B). Significant differences were observed in climbing activity with females climbing by $50 \%$ more than males (climbing frequency: $t_{10}=2.43, p<0.05$, Fig. $4 \mathrm{~A} ; \mathrm{t}_{10}=2.74, \mathrm{p}<0.05$, Fig. $4 \mathrm{~B}$ ).

\section{Discussion}

In the current experiment, sex differences were found in the spontaneous behavior of adult mice, with higher locomotor activity observed in females than males. No differences were found in the coping ability of mice, both females and males habituated to the novel environment similarly, as it was observed as a similar distance travelled in a minute by minute time period. The distance the animals walked around the cage declined approximately to the half in the last minute of the OF if compared to the first minute of the testing in both, 
A
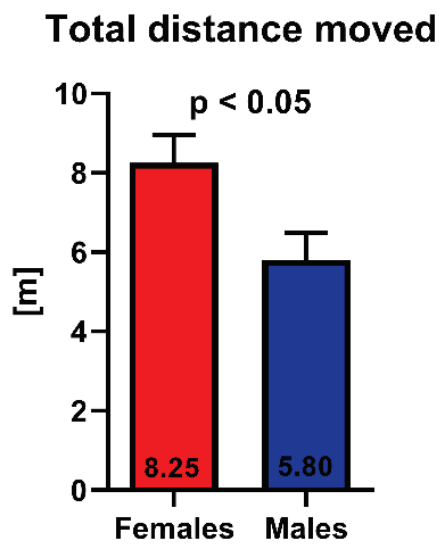

B Average velocity of the movement

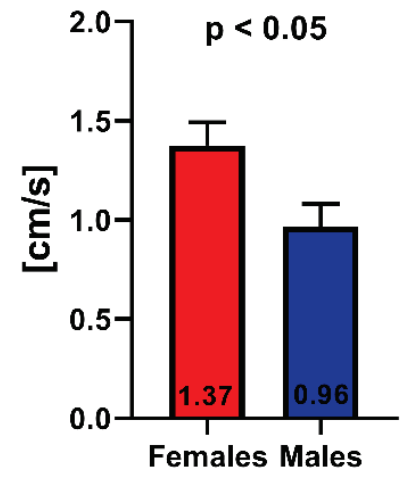

C Distance moved

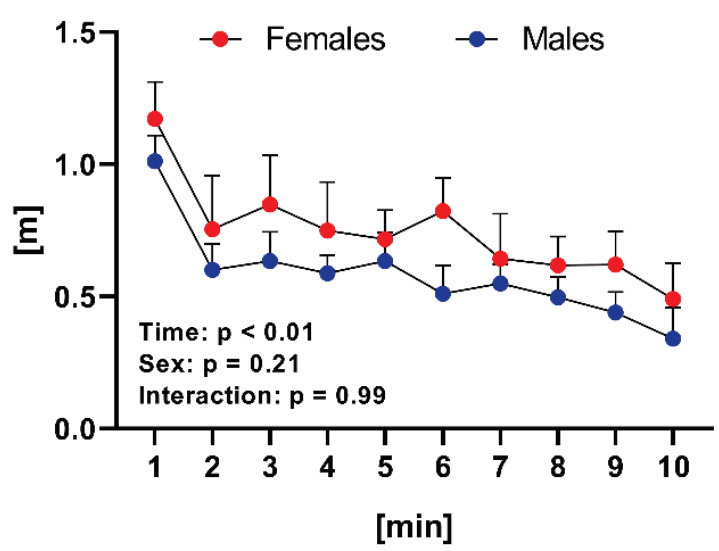

Fig. 2. Horizontal locomotor activity of mice. (A) Total distance moved and (B) Average velocity of the movement. (C) Process of habituation. Significant sex differences were observed, with male mice moving slower and less than females. There was no sex difference in course of habituation. Data are expressed as means + SEM. Females ( $n=6$, red bar) and males $\left(n=6\right.$, blue bar). ${ }^{*} p<0.05$.

A

\section{Rearing}

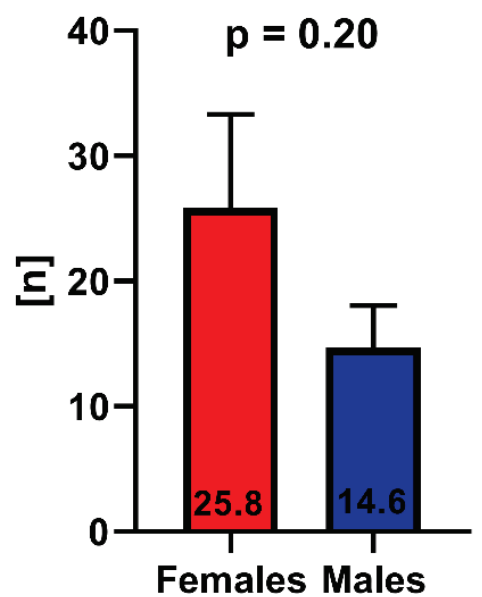

B

\section{Rearing duration}

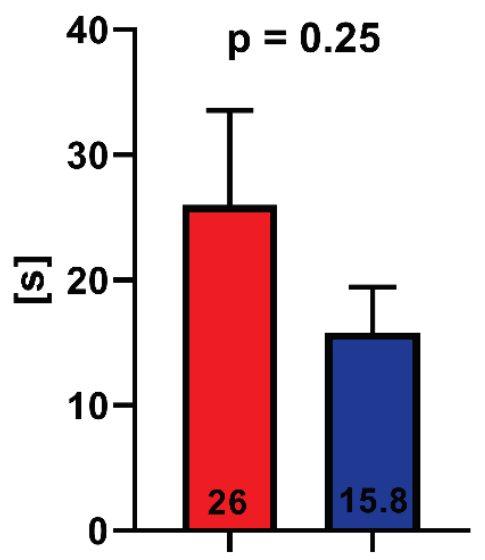

Females Males

Fig. 3. Vertical locomotor activity of mice. (A) Rearing frequency and (B) Time spent with rearing. There were no significant sex differences in rearing activity of mice. Data are expressed as means + SEM. Females $(n=6$, red bar) and males ( $n=6$, blue bar). 
A

Climbing

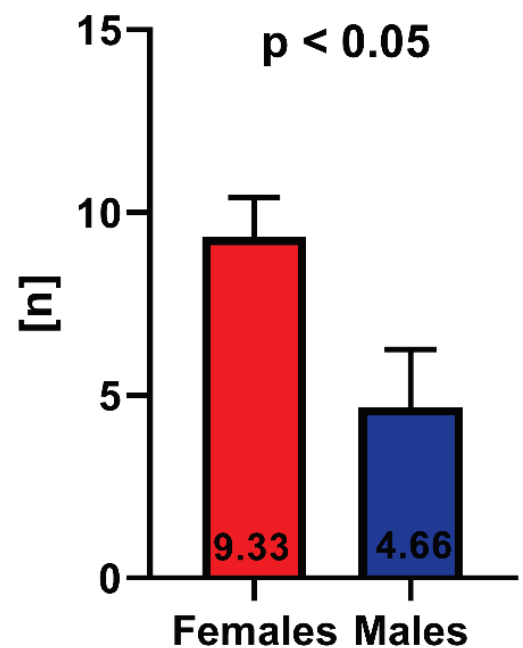

B

\section{Climbing duration}

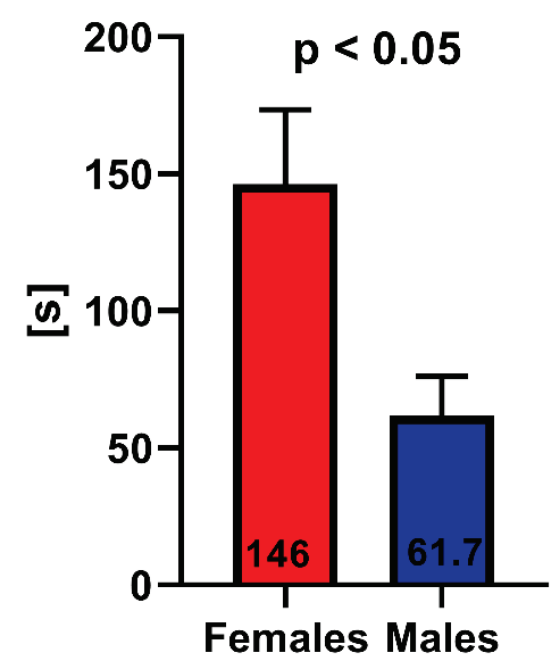

Fig. 4. Grid-climbing activity of mice. (A) Climbing frequency and (B) Time spent with climbing. Significant sex differences were observed, with male mice displaying lower climbing activity than females. Data are expressed as means + SEM. Females ( $n=6$, red bar) and males $\left(n=6\right.$, blue bar). ${ }^{*} p<0.05$.

females and males. Similarly, no sex differences were found in the rearing activity of mice. The most interesting and novel finding of the present study is, however, the higher grid-climbing activity in females compared to males. This finding is interesting even more if taken in account the rearing behavior that did not differ between males and females. Higher grid-climbing activity of females might be a form of spontaneous locomotor activity, which is in general, higher in females than males (Dere et al. 2018). It could be also explained as a higher "curiosity" of females about the unknown environment outside the cage as a part of the exploratory behavior of female mice. According to previously published data, the bar-related activity of mice is a form of repetitive stereotypic-like behavior, however, this study analyzed the behavior of such male mice (Nevison et al. 1999) and did not focus on sex differences in climbing activity of animals. The prevention of cage-lid-related activities increases the anxiety-like behavior of mice (Pietropaolo et al. 2007) thus, it affects the emotional state of animals. Therefore, it is possible that presence of other conspecifics can alter the grid-climbing activity, however, according to our knowledge, there is no experimental study dealing with this phenomenon.

The methods used for performing the OF vary significantly across the laboratories and therefore, the interpretation and mutual comparison of the results is not always straightforward (Karl et al. 2003). The results of the present study are in accordance with the findings of Dere et al. (2018) reporting higher locomotor activity in females than males in a more complex environment used as an $\mathrm{OF}$ (IntelliCage).

During behavioral testing of laboratory rodents, various external factors such as physical factors, timing or presence of the investigator might be the source of bias (Perals et al. 2017, Dere et al. 2018). Therefore, in the present study, we have tried to reduce confounding external factors to a minimum using the automated LABORAS system, allowing the evaluation of the spontaneous behavior of mice without the presence of the observer (Quinn et al. 2006). Worries about the inconsistency of the results related to estrous cycle of females led to a clear minority of behavioral experimental studies including both sexes (Sechzer et al. 1994). However, Fritz et al. confirmed that presence of female mice in an experimental study did not induce a relevant increase of variability in OF activity of mice (Prendergast et al. 2014, Fritz et al. 2017). To follow this suggestion, in the present study, both male and female mice were used. To avoid influence of the estrous cycle on the measured behavioral outcomes, female and male mice were maintained in separate animal rooms during the experiment. It leads to a so-called Lee-Boot effect, which means, that the females have a suppressed estrous cycle and are in anestrus (Ma et al. 1998). Separation of females to another animal room made the female group 
homogenous in hormone levels allowing no influence of different levels of ovarian hormones on behavioral outcomes of the mice. It was necessary, because previous experimental studies have shown that sex hormones affect the behavioral outcomes of rodents across life (e.g. locomotor activity, anxiety, cognitive function) (Mitra et al. 2016, Onaolapo et al. 2016, Domonkos et al. 2017, Domonkos et al. 2018, Jardi et al. 2018) and, in females, behavioral changes occur according to the variation in phases of the estrous cycle (Datta et al. 2016, Datta et al. 2019). Besides, we have resigned to record more animals simultaneously to prevent the effect of the presence of another animal on the behavioral outcomes. Therefore, we have decided to test the spontaneous behavior of a single mouse of both sexes.

This experiment is unique, since it analyzes the behavioral sex differences in intact mice in an observerindependent OF test, particularly in LABORAS. But it is also affected by several limitations. It has previously been demonstrated, that specific behavioral domains of mice in a novel environment differ substantially on the time of day when OF is performed (Valuskova et al. 2019). Thus, the first limitation of our study is that we did not analyze the sex-dependent behavioral changes during the dark (active) phase of the animals. Our study is also limited by short-term observation of mouse behavior; a longer observation period would bring valuable additional information regarding sex differences in the behavioral repertoire of mice in the LABORAS system. In addition, using of different substrains of C57BL/6 mice with a higher sample size would be more valuable for further clarification of the role of grid-climbing activity in behavioral repertoire of the laboratory mouse. However, internal validation of LABORAS system was not performed in this study, the LABORAS system was already validated by Van de Weerd et al. (2001) and Quinn et al. (2003, 2006) suggesting it as a reliable system for automated registration of behavioral parameters in laboratory mice and rats (Van de Weerd et al. 2001, Quinn et al. 2003, Quinn et al. 2006).

In summary, the results of the present experiment indicate higher locomotor activity in female compared to male mice. Besides, female mice exhibited higher grid-climbing activity than males, a "new" sexdependent feature of behavior in laboratory mice. Further studies are needed to elucidate the role of the gridclimbing activity as a part of the spontaneous behavior of laboratory mice. Whether the presence of social partners alters the grid-climbing activity in both sexes needs further clarification.

\section{Conflict of Interest}

There is no conflict of interest.

\section{Acknowledgements}

This study was supported by the Charles University Grant Agency grant 454218 and research programs PROGRES Q35 and PROGRES Q25.

\section{References}

BUTTNER D: Climbing on the cage lid, a regular component of locomotor activity in the mouse. J Exp Anim Sci 34: 165-169, 1991.

DATTA S, SAMANTA D, SINHA P, CHAKRABARTI N: Gender features and estrous cycle variations of nocturnal behavior of mice after a single exposure to light at night. Physiol Behav 164: 113-122, 2016.

DATTA S, SAMANTA D, TIWARY B, CHAUDHURI AG, CHAKRABARTI N: Sex and estrous cycle dependent changes in locomotor activity, anxiety and memory performance in aged mice after exposure of light at night. Behav Brain Res 365: 198-209, 2019.

DERE E, RONNENBERG A, TAMPE B, ARINRAD S, SCHMIDT M, ZEISBERG E, EHRENREICH H: Cognitive, emotional and social phenotyping of mice in an observer-independent setting. Neurobiol Learn Mem 150: 136-150, 2018.

DOMONKOS E, BORBELYOVA V, CSONGOVA M, BOSY M, KACMAROVA M, OSTATNIKOVA D, HODOSY J, CELEC P: Sex differences and sex hormones in anxiety-like behavior of aging rats. Horm Behav 93: $159-165,2017$.

DOMONKOS E, HODOSY J, OSTATNIKOVA D, CELEC P: On the role of testosterone in anxiety-like behavior across life in experimental rodents. Front Endocrinol (Lausanne) 9: 441, 2018.

FRITZ AK, AMREIN I, WOLFER DP: Similar reliability and equivalent performance of female and male mice in the open field and water-maze place navigation task. Am J Med Genet C Semin Med Genet 175: 380-391, 2017. 
JANDOVA K, KOZLER P, LANGMEIER M, MARESOVA D, POKORNY J, RILJAK V: Influence of low-dose neonatal domoic acid on the spontaneous behavior of rats in early adulthood. Physiol Res 63 (Suppl 4): S521-S528, 2014.

JARDI F, LAURENT MR, KIM N, KHALIL R, DE BUNDEL D, VAN EECKHAUT A, VAN HELLEPUTTE L, DEBOEL L, DUBOIS V, SCHOLLAERT D, DECALLONNE B, CARMELIET G: Testosterone boosts physical activity in male mice via dopaminergic pathways. Sci Rep 8: 957, 2018.

KARL T, PABST R, VON HÖRSTEN S: Behavioral phenotyping of mice in pharmacological and toxicological research. Exp Toxicol Pathol 55: 69-83, 2003.

KULESSKAYA N, VOIKAR V: Assessment of mouse anxiety-like behavior in the light-dark box and open-field arena: role of equipment and procedure. Physiol Behav 133: 30-38, 2014.

MA W, MIAO Z, NOVOTNY MV: Role of the adrenal gland and adrenal-mediated chemosignals in suppression of estrus in the house mouse: the lee-boot effect revisited. Biol Reprod 59: 1317-1320, 1998.

MASON GJ: Stereotypies: a critical review. Animal Behaviour 41: 1015-1037, 1991.

MITRA S, BASTOS CP, BATES K, PEREIRA GS, BULT-ITO A: Ovarian sex hormones modulate compulsive, affective and cognitive functions in a non-induced mouse model of obsessive-compulsive disorder. Front Behav Neurosci 10: 215, 2016.

NEVISON CM, HURST JL, BARNARD CJ: Why do male ICR (CD-1) mice perform bar-related (stereotypic) behaviour? Behav Processes 47: 95-111, 1999.

ONAOLAPO OJ, ONAOLAPO AY, OMOLOLU TA, OLUDIMU AT, SEGUN-BUSARI T, OMOLEKE T: Exogenous testosterone, aging, and changes in behavioral response of gonadally intact male mice. $J$ Exp Neurosci 10: 59-70, 2016.

PERALS D, GRIFFIN AS, BARTOMEUS I, SOL D: Revisiting the open-field test: what does it really tell us about animal personality? Animal Behav 123: 69-79, 2017.

PIETROPAOLO S, MINTZ M, FELDON J, YEE BK: The behavioral sequela following the prevention of home-cage grid-climbing activity in C57BL/6 mice. Behav Neurosci 121: 345-355, 2007.

PRENDERGAST BJ, ONISHI KG, ZUCKER I: Female mice liberated for inclusion in neuroscience and biomedical research. Neurosci Biobehav Rev 40: 1-5, 2014.

QUINN LP, STEAN TO, CHAPMAN H, BROWN M, VIDGEON-HART M, UPTON N, BILLINTON A, VIRLEY DJ: Further validation of LABORAS using various dopaminergic manipulations in mice including MPTPinduced nigro-striatal degeneration. J Neurosci Methods 156: 218-227, 2006.

QUINN LP, STEAN TO, TRAIL B, DUXON MS, STRATTON SC, BILLINTON A, UPTON N: LABORAS: Initial pharmacological validation of a system allowing continuous monitoring of laboratory rodent behaviour. J Neurosci Methods 130: 83-92, 2003.

SECHZER JA, RABINOWITZ VC, DENMARK FL, MCGINN MF, WEEKS BM, WILKENS CL: Sex and gender bias in animal research and in clinical studies of cancer, cardiovascular disease, and depression. Ann N Y Acad Sci 736: 21-48, 1994.

SCHWARZ M, JANDOVA K, STRUK I, MARESOVA D, POKORNY J, RILJAK V: Low dose domoic acid influences spontaneous behavior in adult rats. Physiol Res 63: 369-376, 2014.

STURMAN O, GERMAIN PL, BOHACEK J: Exploratory rearing: a context- and stress-sensitive behavior recorded in the open-field test. Stress 21: 443-452, 2018.

VALUSKOVA P, RILJAK V, FORCZEK ST, FARAR V, MYSLIVECEK J: Variability in the drug response of $\mathrm{m} 4$ muscarinic receptor knockout mice during day and night time. Front Pharmacol 10, 2019.

VAN DE WEERD H, BULTHUIS R, BERGMAN A, SCHLINGMANN F, TOLBOOM J, VAN LOO P, REMIE R, BAUMANS V, VAN ZUTPHEN L: Validation of a new system for the automatic registration of behaviour in mice and rats. Behav Processes 53: 11-20, 2001.

WALSH RN, CUMMINS RA: The open-field test: a critical review. Psychol Bull 83: 482-504, 1976. 